\title{
Evaluation of Six Models to Estimate Ascospore Maturation in Venturia pyrina
}

H. Eikemo, Norwegian Institute for Agricultural and Environmental Research, Plant Health and Plant Protection Division, 1432 Ås, Norway; D. M. Gadoury, Department of Plant Pathology, Cornell University, New York State Agricultural Experiment Station, Geneva, NY 14456; R. A. Spotts, Oregon State University Mid-Columbia Agricultural Research and Extension Center, Hood River 97031; O. Villalta, Biosciences Research Division, Department of Primary Industries, Knoxfield, Victoria, Australia; P. Creemers, Proefcentrum Fruitteelt-Applied Scientific Research, Department of Mycology, B-3800 Sint-Truiden, Belgium; R. C. Seem, Department of Plant Pathology, Cornell University; and A. Stensvand, Norwegian Institute for Agricultural and Environmental Research, Plant Health and Plant Protection Division

\begin{abstract}
Eikemo, H., Gadoury, D. M., Spotts, R. A., Villalta, O., Creemers, P., Seem, R. C., and Stensvand, A. 2011. Evaluation of six models to estimate ascospore maturation in Venturia pyrina. Plant Dis. 95:279-284.

Estimates of ascospore maturity generated by models developed for Venturia pyrina in Victoria, Australia (NV and SV), Oregon, United States (OR), and Italy (IT) or for $V$. inaequalis in New Hampshire, United States (NH-1) or modified in Norway (NH-2) were compared with observed field ascospore release of $V$. pyrina from 21 site-year combinations. The models were also compared with ascospore release data from laboratory assays. In the laboratory assays, the forecasts of the $\mathrm{NH}-1$ and $\mathrm{NH}-2$ models provided the best fit to observed spore release. Under field conditions, the lag phases and slope coefficients of all models differed from those of observed release of ascospores.

Identifying the precise time of bud break of pear to initiate degree-day accumulation was problematic at both Australian sites. This resulted in a higher deviance between bud break and first released ascospore compared with the sites in Norway and Belgium. Linear regressions of observed release against forecasted maturity generated similarly high concordance correlation coefficients. However, where differences were noted, they most often favored models that included adjustment for dry periods. The NH-2, IT, and NV models using pooled data also provided the most accurate estimates of $95 \%$ ascospore depletion, a key event in many disease management programs.
\end{abstract}

Pear scab and apple scab, caused by the ascomycetes Venturia pyrina Aderh. and V. inaequalis (Cooke) G. Winter, respectively, are important diseases of their hosts worldwide (8). The fungi survive primarily as pseudothecia in leaf litter in the orchards. Ascospores are released from pseudothecia in leaf litter by rain or heavy dew beginning near the time of bud break and for 2 to 3 months thereafter, with a peak in release between early bloom and petal fall of their respective hosts $(2,4,6,17)$. Overwinter survival of mycelia within buds or stromatic tissue within lesions in the bark (wood scab) has also been reported in some climates, and can serve as a source of inoculum in the spring. Where wood scab occurs, viable lesions have been found primarily in second-season and, to some extent, third-season shoots $(5,10,19)$. Seasonal development of ascospores in $V$. pyrina has been studied using visual examinations of crushed ascocarps $(17,23)$, and collection of ascospores in the field using spore traps $(6,17,23)$.

For both $V$. pyrina $(15,17,23)$ and $V$. inaequalis (2), degree-day (DD)-driven mathematical models of ascospore maturation have been developed. Such temperature-driven models offer several benefits for pome fruit disease advisory programs. For example, they can be inexpensively applied over broad areas and provide site-specific estimates of ascospore maturity and release if coupled with on-site weather observations or site-specific weather forecasts (25). However, none of the $V$. pyrina models have been validated outside of the geographical region in which they were developed. Although such validations often involve comparisons with ascospore discharge as measured by volumetric spore traps, there are many limitations to the validation of ascospore maturity models using ascospore discharge data. For example, moisture is required for release of ascospores of $V$. pyrina and $V$. inaequalis

Corresponding author: H. Eikemo, E-mail: haavard.eikemo@bioforsk.no

Accepted for publication 8 October 2010.

doi:10.1094/PDIS-02-10-0125

(C) 2011 The American Phytopathological Society
$(4,11,15,20,24)$ under both laboratory and field conditions. Unless rainfall is frequent and occurs in sufficient quantities, cumulative catches from volumetric spore traps can lag behind cumulative ascospore maturity due to incomplete release. Excessively low or infrequent rainfall may also suppress maturation, and could potentially cause mortality in the population of pseudothecia, as was described for $V$. inaequalis by O'Leary and Sutton (13). To varying degrees, these climatic factors influence the processes of ascospore maturation and release in different climates, and their effect may also differ between years within similar climates. Because protracted dry periods will delay ascospore maturation and release and, therefore, prolong the ascospore release season of $V$. pyrina $(15,23)$ and $V$. inaequalis $(4,14,16,20)$, stopping DD accumulation during protracted dry periods has been suggested as an adjustment to make DD-driven models more applicable under relatively dry conditions $(4,15,20,24)$.

Although the above factors may result in ascospore maturity, as predicted by the various models, that diverges from the cumulative capture of ascospores by volumetric spore traps, a number of extant models could be compared with a common set of observations. Whereas uncontrolled factors could inflate the differences between expected maturity and observed ascospore trapping, especially near the midrange of the maturation curves, the predicted date of $95 \%$ ascospore maturity and the date of exhaustion of the airborne ascospore supply would be most likely to coincide. This also assumes that a suitable rain event occurs near the end of the ascospore maturation process. The end of the ascospore release season has been an important event in management of pear scab, because it often coincides with a shift toward a less intensive period of fungicide applications once the threat of ascosporic infection has passed.

Our objective was to validate and compare the performance of six temperature-driven models for their ability to estimate the cumulative maturation of ascospores of $V$. pyrina. The first model was developed for apple scab in New Hampshire (2) and later revised to incorporate a rainfall threshold to halt DD accumulation during extended periods without rain (20). The other models were originally developed for pear scab in Italy (15), Oregon (17), and Victoria, Australia (23). For the validation studies, we used an 
independent set of observations consisting of spore trap catches from 21 site-year combinations from Australia, Belgium, and Norway.

\section{Materials and Methods}

Field validation data for models. Data used to evaluate the models were expressed as cumulative seasonal ascospore releases of $V$. pyrina recorded by Burkard 7-day recording volumetric spore traps (Burkard Manufacturing Co Ltd., Rickmansworth, Hertfordshire, UK) at Ås $\left(59^{\circ} 40^{\prime} 11.93 \mathrm{~N}, 10^{\circ} 46^{\prime} 03.16 \mathrm{E}\right)$ in southeastern Norway (6 years), Gorsem ( $\left.50^{\circ} 49^{\prime} 59.99 \mathrm{~N}, 5^{\circ} 09^{\prime} 52.93 \mathrm{E}\right)$ in eastern Belgium (5 years), and Arthurs Creek (37 $37^{\prime} 15.20 \mathrm{~S}$, $\left.145^{\circ} 08^{\prime} 08.60 \mathrm{E}\right)$ in southern Victoria and Tatura $\left(36^{\circ} 26^{\prime} 28.13 \mathrm{~S}\right.$, $145^{\circ} 13^{\prime} 40.68 \mathrm{E}$ ) in northern Victoria (5 years from each site). At all sites, the spore traps were placed in pear orchards during the growing season, with heavily infected and overwintered pear leaves surrounding the traps as previously described $(20,23)$. In Norway and Belgium, the soil of the study area was drenched with benzimidazole at $0.5 \mathrm{~g}$ a.i./liter, to prevent earthworms from consuming the leaf litter during winter and spring. The spore traps were set to sample air at approximately 10 liters/min. Ascospores were collected by impaction on the surface of a plastic tape attached to a clock cylinder within the Burkard trap. This tape was removed and prepared for microscopic examination and enumeration of the ascospores (3). Electronic data loggers (models CR10 or CR10X; Campbell Scientific, Inc., Logan, UT) provided records of precipitation, temperature, relative humidity, and leaf wetness (wetness sensing grids; minutes of leaf wetness per hour as output) at each site. Temperature and relative humidity were recorded at heights of 1.5 to $2 \mathrm{~m}$ above the ground in weather shelters or radiation shields. The climatic data used in the analysis from Norway and Belgium were based on mean values calculated from hourly records and from Australian daily means.

Laboratory validation data for models. Diseased pear leaves were used to simulate seasons of ascospore maturation and discharge in the laboratory. The samples overwintered on the orchard floor and were collected at bud break. Eight samples from three different countries were tested, including one from France (Bergerac), three from Belgium (Gorsem), and four from Norway (Ås), collected between 2002 and 2006. The leaf samples were collected at bud break and air dried to stop further maturation. Samples from Belgium and France were sent to Norway, and all samples were kept frozen at $-18^{\circ} \mathrm{C}$ thereafter, until the start of the experiments. Three replicates, each containing 10 leaf discs (12 $\mathrm{mm}$ in diameter), were removed from individual leaves and placed between two layers of nylon mesh ( 5 by $20 \mathrm{~cm}$, rolled into a cylinder). Samples were stored at $20^{\circ} \mathrm{C}$ in a saturated atmosphere in darkness between tests, and ascospores were collected every 2 to 3 days by shaking in $50 \mathrm{ml}$ of distilled water for $2 \mathrm{~h}$. The number of ascospores released was determined by filtering the suspension through a $0.65-\mu \mathrm{m}$ membrane (Millipore, Billerica, MA) using vacuum and a Buchner funnel. The filter was mounted on a microscopic slide, two axial transects were scanned under a light microscope at $\times 400$, and the number of ascospores was adjusted according to the proportion of the total volume examined as described by Gadoury and MacHardy (3).

Models. All models tested used DD accumulation (base $=0^{\circ} \mathrm{C}$; 2) to estimate the proportion of mature ascospores. Detailed information about the models is given in Table 1. The New Hampshire $(\mathrm{NH})$ models were originally developed for apple scab but, in this analysis, bud break of pear (early cultivars) was used as the biofix.

Model evaluation. DDs were calculated based on daily temperatures for all the spore-trapping data and used in the models described earlier. The models were also compared with the data from the laboratory experiments. The resulting estimated percentages were regressed against the observed (trapped) number of ascospores. Concordance correlation coefficients (CCC; 7) were used to evaluate the degree to which pairs of observations are distributed around a $45^{\circ}$ line through the origin. CCC measured the agreement between two variables, and equals 1 when there is perfect agreement and 0 when the plot of observed versus predicted is a random scatter. In addition, the slope and intercept of the regression line were tested for equality to 1 and 0 , respectively, by a Students $t$ test. If the $t$ tests for slope $(b)$ or intercept $(a)$ were not significant $(P \geq 0.05)$, the model was considered an accurate estimator of the data. The distribution of errors made by the different models (defined as observed minus predicted) was also considered. In addition, the estimated date of $95 \%$ ascospore depletion for the different models was compared with the observed date of $95 \%$ ascospores trapped. All data analysis was performed using Minitab Statistical Software, State College, PA.

\section{Results}

Initial ascospore release and tree phenology. The occurrence of available susceptible tissue (pear bud break) and initial detection (trapping) of ascospores generally coincided in Norway and Belgium using DDs or days as comparison (Table 2). In two of the years from Norway and three of the years from Belgium, the difference between bud break and first spore release was more than 10 days. In only 1 year were ascospores trapped prior to bud break in Belgium (Table 2). In Australia, ascospores were released prior to bud break in 6 of 10 years (Table 2). In southern Victoria in

Table 1. Six models evaluated for their ability to predict ascospore release of Venturia pyrina

\begin{tabular}{|c|c|c|c|c|c|c|}
\hline Origin & Model $^{\mathbf{a}}$ & Form & Equation & $\mathbf{Z}(\mathbf{D D})^{\mathbf{b}}$ & $\begin{array}{l}\text { DD }\left(\text { base } 0^{\circ} \mathbf{C}\right) \\
\text { restrictions }\end{array}$ & Biofix $^{d}$ \\
\hline Oregon (17) & OR & Monomolecular & $\begin{array}{l}Y_{O R}=\{1-\exp \\
[-Z(D D)]\} \times 100\end{array}$ & $\begin{array}{r}Z(D D)=0.00415 \cdot D D- \\
0.00797 \mathrm{DD}_{50 \%}=168.2\end{array}$ & None & $\begin{array}{l}\text { First ascospore } \\
\text { trapped }\end{array}$ \\
\hline S. Victoria, Australia (23) & SV & $\begin{array}{l}\text { Logistic } \\
Z=\text { Logit }\end{array}$ & $\begin{array}{l}Y_{S V}=\{\{1+\exp \\
\left.[-Z(D D)]\}^{-1}\right\} \times 100\end{array}$ & $\begin{array}{c}Z(D D)=0.0129 \cdot D D- \\
2.132 \mathrm{DD}_{50 \%}=165.3\end{array}$ & None & $\begin{array}{l}\text { First ascospore } \\
\text { trapped }\end{array}$ \\
\hline N. Victoria, Australia (23) & NV & $\begin{array}{l}\text { Logistic } \\
Z=\text { Logit }\end{array}$ & $\begin{array}{l}Y_{N V}=\{\{1+\exp \\
\left.[-Z(D D)]\}^{-1}\right\} \times 100\end{array}$ & $\begin{array}{c}Z(D D)=0.00413 \cdot D D- \\
4.997 \mathrm{DD}_{50 \%}=121\end{array}$ & $\begin{array}{l}\text { DD accumulation when } \\
\text { rain }>0.2 \mathrm{~mm} / \text { day or }>12 \\
\mathrm{~h} \mathrm{w} / \mathrm{RH}>80 \%\end{array}$ & $\begin{array}{l}\text { First ascospore } \\
\text { trapped }\end{array}$ \\
\hline Italy (15) & IT & $\begin{array}{l}\text { Gompertz } \\
\mathrm{Z}=\text { Gompit }\end{array}$ & $\begin{array}{l}Y_{I T}=\{\exp \{-\exp \\
[-Z(D D)]\}\} \times 100\end{array}$ & $\begin{array}{l}Z(D D)=0.015 \cdot D D- \\
1.6696 D_{50 \%}=135.7\end{array}$ & $\begin{array}{l}\text { DD accumulation when } \\
\text { rain }>0.2 \mathrm{~mm}^{-1} \text { day }^{-1} \text { or } \\
\text { VPD }<4 \mathrm{~h} \mathrm{~Pa}^{\mathrm{e}}\end{array}$ & $\begin{array}{l}\text { First ascospore } \\
\text { trapped }\end{array}$ \\
\hline New Hampshire (2) & NH-1 & $\begin{array}{l}\text { Normal } \\
Z=\text { Probit }\end{array}$ & $\begin{array}{c}Y_{N H}=\{1 / 2\{1+e r f \\
[Z(D D)]\}\} \times 100\end{array}$ & $\begin{array}{l}Z(D D)=0.01 \cdot D D- \\
2.51 \mathrm{DD}_{50 \%}=251\end{array}$ & None & $\begin{array}{l}\text { Bud break } \\
\text { (pear) }\end{array}$ \\
\hline New Hampshire (20) & $\mathrm{NH}-2$ & $\begin{array}{l}\text { Normal } \\
Z=\text { Probit }\end{array}$ & $\begin{array}{c}Y_{N H}=\{1 / 2\{1+e r f \\
[Z(D D)]\}\} \times 100\end{array}$ & $\begin{array}{l}Z(D D)=0.01 \cdot D D- \\
2.51 \mathrm{DD}_{50 \%}=251\end{array}$ & $\begin{array}{l}7 \text { rain free days halts DD } \\
\text { accumulation }\end{array}$ & $\begin{array}{l}\text { Bud break } \\
\text { (pear) }\end{array}$ \\
\hline
\end{tabular}

${ }^{a}$ Models developed for Venturia pyrina in Oregon (OR), southern Victoria (SV), northern Victoria (NV), and Italy (IT) or for V. inaequalis in New Hampshire (NH-1) and modified in Norway (NH-2).

${ }^{\mathrm{b}} Z(D D)$ is the equation for how degree-days are accumulated by the different models, and $\mathrm{DD}_{50 \%}$ gives the number of degree-days where the model reaches $50 \%$ maturity.

${ }^{\mathrm{c}}$ Conditions that start or stop degree-day accumulation. $\mathrm{RH}=$ relative humidity.

${ }^{\mathrm{d}}$ Event that triggers the start of the models.

e Vapor pressure deficit (VPD) calculated from temperature and relative humidity (1). 
1998, the first ascospores were trapped 10 days (115 DDs) after bud break, even though rain events were recorded during 5 of the 10 days between bud break and first ascospores trapped (Table 2).

Comparison of models. A comparative illustration of the models using a common data set (assuming continuous wetness) demonstrated the different typical responses of each model (Fig. 1). The Oregon (OR) model had a monomolecular structure with a long tail toward the end, whereas the other models had a sigmoid shape with an initial lag phase of varying length. The northern Victoria (NV) model only accumulated DDs on days with rain, which gave a very steep slope $\left(\mathrm{DD}_{50 \%}=121\right)$ compared with the other models $\left(\mathrm{DD}_{50 \%}\right.$ $=165$ to 251). There were no differences between New Hampshire (NH-1) or NH modified in Norway (NH-2) (no dry periods); therefore, a single line represented the two variations.

Field validation data for models. In linear regressions of predicted cumulative ascospores against observed cumulative ascospores trapped, the NH-1 model yielded the highest overall concordance correlation coefficient (0.88), and only for data from Belgium was the intercept or slope significantly different from 0 or 1 , respectively (Table 3 ). Of all sites evaluated, the $\mathrm{NH}-1$ model best fitted the data from Norway, with a CCC of 0.96 , while the lowest CCC value (0.77) for the $\mathrm{NH}-1$ model was obtained with data from southern Victoria. The distribution of errors (Fig. 2) showed a very tight grouping of the middle $50 \%$ of the data, with an interquartile range from -5.4 to 5.6 (Fig. 2). The average error in predicting 95\% spore release (Table 4) was 8.8 days, and the variation among sites was low.

The NH-2 model yielded a slightly lower overall CCC than was obtained for the $\mathrm{NH}-1$ model $(0.87$ versus 0.88$)$ and, for two of four locations, the slope and intercept were equal to 1 and 0 , respectively (Table 3 ). The model slightly underestimated the percentage of ascospores released in the beginning of the season (Fig. $2)$, and the interquartile range ( -1.9 to 15.2$)$ was wider than observed for the NH-1 model (Fig. 2). The NH-2 model exhibited the lowest mean error in estimating the date of $95 \%$ cumulative trapping of ascospores at all sites except southern Victoria (Table 4).

The NV model yielded results similar to those obtained for the NH-2 model (Table 3) and slightly underestimated the percentages of ascospores trapped early in the season (Fig. 2). The distribution of errors showed an interquartile range of -2.5 to 12.5 (Fig. 2).
Accuracy in predicting $95 \%$ ascospore trapping for southern Victoria was relatively low (mean deviation of 9 days).

In contrast, the southern Victoria (SV) model overestimated ascospore release early in the season, as indicated by the relatively high intercept value obtained when model predictions were regressed against observed ascospore trapping in Norway, Belgium, and northern Victoria (Table 3). The distribution of errors (Fig. 2) was shifted negatively, with an interquartile range of -19.7 to 0 (Fig. 2). The SV model generally predicted $95 \%$ ascospore maturation too early for all sites except southern Victoria.

The OR model performed similarly to the SV model and overestimated the percentage of ascospores released early in the season, and the distribution of errors was skewed toward negative values, with an interquartile range of -14.0 to 7.9 (Fig. 2). The monomolecular structure of the model resulted in a shallow slope $\left(\mathrm{DD}_{50 \%}=\right.$ 168 and $\left.\mathrm{DD}_{95 \%}=725\right)$ in the cumulative distribution of ascospore maturity (Fig. 1), which contributed to the error (20 days) in estimating the date of $95 \%$ ascospore trapping (Table 4). The fit of the model to the observations produced very few outliers (Fig. 2), and

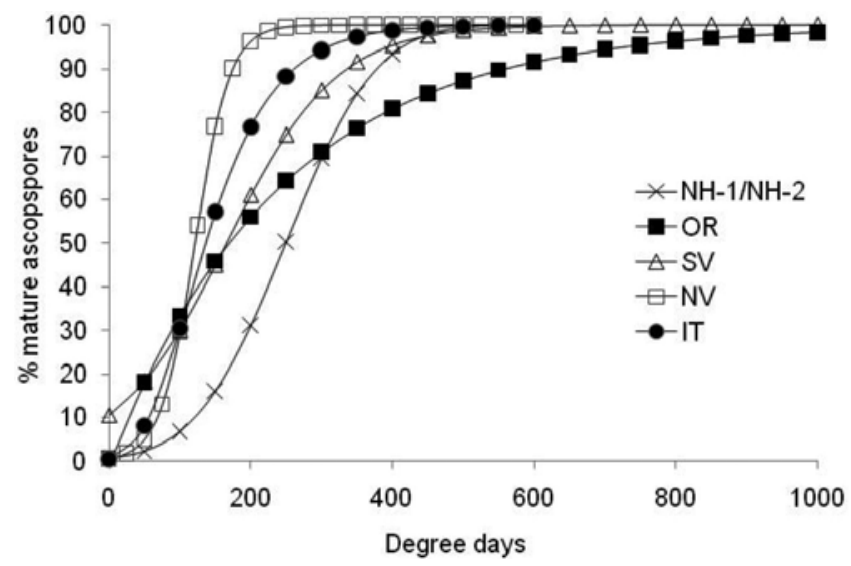

Fig. 1. Comparative results of five ascospore maturity models developed for Venturia pyrina in southern Victoria (SV), northern Victoria (NV), Oregon (OR), and Italy (IT) or for $\mathrm{V}$. inaequalis in New Hampshire (NH-1) and modified in Norway (NH2 ), using an arbitrary set of degree-days (0 to 1.000 in steps of 50 ).

Table 2. Date of bud break of pear fruit buds and date and corresponding degree-day accumulations (base $=0^{\circ} \mathrm{C}$ ) of first detection of airborne ascospores of Venturia pyrina in four locations in Norway, Belgium, and Australia

\begin{tabular}{|c|c|c|c|c|}
\hline Location, year & Date of bud break & First spores trapped & Degree-days $^{a}$ & First rain after bud break \\
\hline \multicolumn{5}{|l|}{ Ås, Norway } \\
\hline 2001 & 24 April & 24 April & 0 & 24 April \\
\hline 2002 & 10 April & 12 April & 18 & 12 April \\
\hline 2003 & 14 April & 27 April & 108 & 26 April \\
\hline 2005 & 18 April & 29 April & 80 & 29 April \\
\hline 2006 & 25 April & 26 April & 7 & 25 April \\
\hline 2007 & 13 April & 22 April & 72 & 19 April \\
\hline \multicolumn{5}{|l|}{ Gorsem, Belgium } \\
\hline 2002 & 26 February & 13 March & 91 & 6 March \\
\hline 2003 & 20 March & 30 March & 99 & 29 March \\
\hline 2004 & 16 March & 20 March & 50 & 19 March \\
\hline 2005 & 23 March & 24 March & 13 & 24 March \\
\hline 2006 & 4 April & $26 \mathrm{March}$ & -82 & * \\
\hline \multicolumn{5}{|c|}{ Northern Victoria, Australia } \\
\hline 1993 & 10 September & 2 September & -104 & $*$ \\
\hline 1994 & 15 September & 5 September & -106 & * \\
\hline 1996 & 12 September & 4 September & -83 & $*$ \\
\hline 1997 & 15 September & 4 September & -127 & * \\
\hline 1998 & 8 September & 11 September & 33 & 11 September \\
\hline \multicolumn{5}{|c|}{ Southern Victoria, Australia } \\
\hline 1992 & 9 September & 9 September & 0 & 9 September \\
\hline 1993 & 6 September & 5 September & -8 & $*$ \\
\hline 1994 & 7 September & 3 September & -29 & * \\
\hline 1997 & 4 September & 8 September & 40 & 4 September \\
\hline 1998 & 1 September & 11 September & 115 & 2 September \\
\hline
\end{tabular}

\footnotetext{
${ }^{a}$ Degree-days between first spore release and bud break. Negative values indicate spore release before bud break.
}

${ }^{b}$ Date of first rain event after bud break; an asterisk indicates that first spore release was before bud break. 
this was reflected in the relatively high CCC (0.85), despite the intercept value of $24.1 \%$ (significantly different from $0 ; P<0.001$ ).

The model developed for Italy (IT) overestimated the number of ascospores released early in the season for Belgium and northern Victoria, as indicated by relatively low slope coefficients ( 0.71 to 0.95 ) and an intercept significantly higher than 0 for all sites except Norway, when expected cumulative ascospores was regressed against observed cumulative ascospores trapped. Errors associated with estimated dates of $95 \%$ spore release were relatively low for Belgium and southern Victoria but averaged 10 days too late for Norway and 11 days too early for northern Victoria (Table 4). The distribution of errors (Fig. 2) showed a relatively tight grouping of the middle $50 \%$ of the data (interquartile range from -7.9 to 3.8 ) and a majority of negative values due to overestimation of mature ascospores early in the season (Fig. 2). This also resulted in a relatively high average CCC of 0.88 (Table 3 ) despite the high overall intercept of $12.4 \%$ (Table 3).

The average CCC (all models) for data from Norway (0.84) and Belgium (0.90) was higher than for the data from southern Victoria $(0.79)$ and significantly higher $(P=0.05)$ than for data from northern Victoria (0.76). There were no significant differences in average CCC among models when data from all sites were pooled (data not shown).

Laboratory validation data for models. The cumulative distributions of ascospore release from pear leaf samples collected in Belgium, France, and Norway were similar (Fig. 3), generally of a sigmoid shape, reaching 50\% near 250 DDs and 100\% near 600 DDs after initial ascospore release (Fig. 3). The pooled laboratory data was best described by the NH-1 model, with a CCC of 0.98 , and the slope and intercept were not significantly different from 1 and 0 , respectively (Table 3 ). In the laboratory experiments, leaf moisture content was not a limiting factor; therefore, DDs accumulated continuously. Consequently, the performance of the NH-1 and NH-2 models was identical (Table 3). The NV model had a higher intercept and a lower slope compared with the NH models, and a CCC value of 0.70 (Table 3). The SV model overestimated the number of ascospores early in the season, indicated by an intercept of $19.0 \%$ (Table 3). The OR model yielded a CCC of 0.89 but a relatively high intercept of $21.3 \%$ (Table 3 ). Moreover, the IT model yielded a relatively low CCC of 0.56 (Table 3 ).

\section{Discussion}

In the management of pear scab, models to estimate the maturity of ascospores are potentially useful to predict the start and end of the primary season and to identify periods of relatively high risk when the maturation process is proceeding rapidly (i.e., when airborne ascospore densities could potentially reach high levels if rain occurred). These are key events in disease management programs and determine when fungicide applications are first applied and when they may be reduced or the interval between applications extended. We were able to not only evaluate model performance against new data from diverse geographic regions and climates but also compare the models to each other against a common set of diverse observations of seasonal ascospore release.

There were substantial differences among the six models evaluated in this study in how they depicted an idealized cumulative distribution of ascospore maturation and in how DDs are accumulated or ignored based upon moisture thresholds. The SV and OR models lack an initial lag phase that is present in all the other models whereas, in the IT model, the lag phase is relatively short. The OR model is monomolecular (17) and, thus, also lacks an initial lag phase. An initial lag phase is typical of previously reported cumulative distributions of ascospore maturity and trapping in $V$. inaequalis $(2,20)$ and in some $(6,23)$ but not all $(18)$ previous studies of $V$. pyrina. An initial lag phase in cumulative distributions was

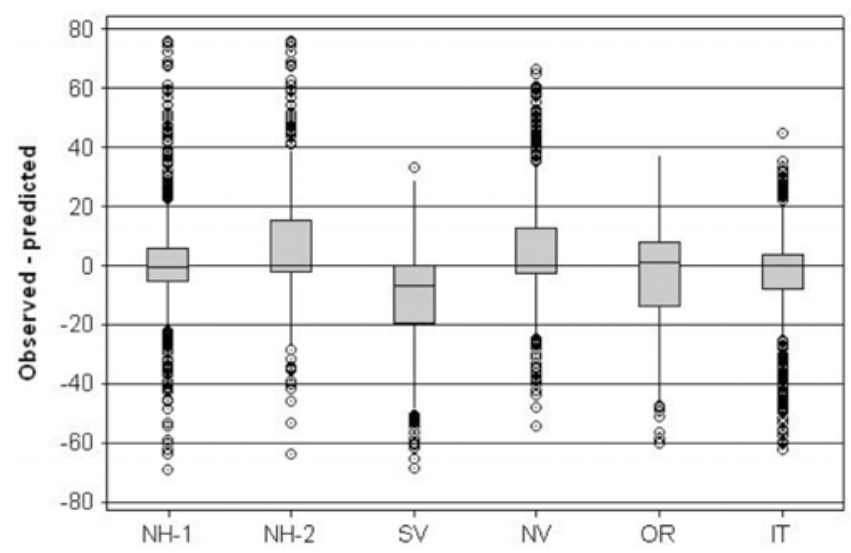

Fig. 2. Distribution of errors made by six different models, shown as observed predicted percentage of ascospores trapped. Models were developed for Venturia pyrina in southern Victoria (SV), northern Victoria (NV), Oregon (OR), and Italy (IT) or for $\mathrm{V}$. inaequalis in New Hampshire (NH-1) and modified in Norway $(\mathrm{NH}-2)$. Boxes contain $50 \%$ of the data, the whiskers extend to the upper and lower quartiles, and the points are outliers.

Table 3. Linear regression of observed release of ascospores versus predicted number of mature ascospores of Venturia pyrina estimated by the six models evaluated in this study ${ }^{\mathrm{a}}$

\begin{tabular}{|c|c|c|c|c|c|c|}
\hline \multirow[b]{2}{*}{ Location $^{c}$} & \multicolumn{6}{|c|}{ Models evaluated $^{\mathbf{b}}$} \\
\hline & NH-1 & NH-2 & SV & NV & OR & IT \\
\hline Norway & $\begin{array}{c}y=0.99 x+2.65 \\
(0.96)\end{array}$ & $\begin{array}{l}y=1.05 x-12.3^{* *} \\
(0.90)\end{array}$ & $\begin{array}{c}y=0.72 * * x+ \\
31.2 * *(0.84)\end{array}$ & $\begin{array}{l}y=1.11^{* *} x- \\
15.36^{* *}(0.90)\end{array}$ & $\begin{array}{c}y=0.65 * * x+ \\
27.9 * *(0.87)\end{array}$ & $\begin{array}{c}y=0.95 * x-2.06 \\
\text { CCC }=0.94\end{array}$ \\
\hline Belgium & $\begin{array}{l}y=0.94 * x+11.0 * * \\
(0.91)\end{array}$ & $\begin{array}{c}y=0.99 x+1.83 \\
(0.98)\end{array}$ & $\begin{array}{c}y=0.77 * * x+ \\
27.2 * *(0.86)\end{array}$ & $\begin{array}{l}y=0.94 x+6.84 * * \\
(0.92)\end{array}$ & $\begin{array}{c}y=0.70 * * x+ \\
24.3 * *(0.89)\end{array}$ & $\begin{array}{l}y=0.87 * * x+ \\
13.09 * *(0.94)\end{array}$ \\
\hline S. Victoria & $\begin{array}{c}y=0.95 x-3.03 \\
(0.77)\end{array}$ & $\begin{array}{c}y=0.94 x-2.94 \\
(0.77)\end{array}$ & $\begin{array}{l}y=0.91 * x+5.37 * \\
(0.91)\end{array}$ & $\begin{array}{c}y=1.01 x-6.59 \\
(0.77)\end{array}$ & $\begin{array}{c}y=0.80 * * x+ \\
6.94 * *(0.88)\end{array}$ & $\begin{array}{c}y=0.96 x+4.16 \\
(0.90)\end{array}$ \\
\hline N. Victoria & $\begin{array}{c}y=0.95 x-5.03 \\
(0.83)\end{array}$ & $\begin{array}{l}y=0.90 * x-4.80 \\
(0.81)\end{array}$ & $\begin{array}{c}y=0.67 * * x+ \\
35.0 * *(0.74)\end{array}$ & $\begin{array}{l}y=0.89 * x+0.27 \\
(0.88)\end{array}$ & $\begin{array}{l}y=0.61 * * x+ \\
31.4 * *(0.78)\end{array}$ & $\begin{array}{l}y=0.71 * * x+ \\
33.95 * *(0.74)\end{array}$ \\
\hline N. and S. Victoria & $\begin{array}{l}y=0.95 x-4.3 \\
(0.80)\end{array}$ & $\begin{array}{l}y=0.93 * x-4.16 \\
(0.79)\end{array}$ & $\begin{array}{c}y=0.75 * * x+ \\
23.0 * *(0.82)\end{array}$ & $\begin{array}{l}y=0.94 * x-2.60 \\
(0.83)\end{array}$ & $\begin{array}{c}y=0.67 * * x+ \\
21.5 * *(0.82)\end{array}$ & $\begin{array}{l}y=0.80 * * x+ \\
21.9 * *(0.81)\end{array}$ \\
\hline All sites & $\begin{array}{l}y=0.96 * x+1.8 \\
(0.88)\end{array}$ & $\begin{array}{l}y=0.98 x-5.00^{* *} \\
(0.87)\end{array}$ & $\begin{array}{c}y=0.75 * * x+ \\
26.5^{* *}(0.83)\end{array}$ & $\begin{array}{l}y=0.99 x-3.81^{* *} \\
(0.87)\end{array}$ & $\begin{array}{l}y=0.67 * * x+ \\
24.1 * *(0.85)\end{array}$ & $\begin{array}{l}y=0.86 * * x+ \\
12.37 * *(0.88)\end{array}$ \\
\hline Lab data & $\begin{array}{l}y=1.02 x-0.58 \\
(0.98)\end{array}$ & n.a. ${ }^{d}$ & $\begin{array}{l}y=0.89 * x+19.0 * * \\
(0.87)\end{array}$ & $\begin{array}{c}y=0.76 x^{* *}+ \\
33.6^{* *}(0.70)\end{array}$ & $\begin{array}{c}y=0.70^{* *} x+ \\
21.3^{* *}(0.89)\end{array}$ & $\begin{array}{l}y=0.81 * * x+ \\
25.8 * *(0.56)\end{array}$ \\
\hline
\end{tabular}

${ }^{a}$ Results from linear regressions of observed $(x)$ versus predicted $(y)$, shown as concordance correlation coefficient (CCC; 7). Slope and intercept of the regression line were tested for equality to 1 and 0 , respectively, by Students $t$ test. Significant differences are marked with asterisks (* and $* *$ indicate $P<$ 0.05 and 0.01 , respectively). Fitted lines where slope and intercept are equal to 1 and 0 , respectively, are marked in bold.

${ }^{\mathrm{b}}$ Models developed for V. pyrina in southern Victoria (SV), northern Victoria (NV), Oregon (OR), and Italy (IT) or for V. inaequalis in New Hampshire (NH1) and modified in Norway (NH-2).

${ }^{c}$ Spore sampling data from two sites in Australia (southern [S.] and northern [N.] Victoria) and one site each in Belgium and Norway.

${ }^{\mathrm{d}}$ Because of continuous wetness during laboratory experiments, degree-day accumulation in NH-2 was identical to NH-1. 
also evident in ascospore trapping data from Norway, Belgium, and, in most years, from northern Victoria. Consequently, the SV, IT, and OR models consistently overestimated ascospore release early in the season. The southern Victoria site has a higher mean annual rainfall than that in northern Victoria (22), and amount of precipitation during the month prior to bud break has been shown to affect the number of mature ascospores at bud break in $V$. inaequalis (21). Together with undetected, minor ascospore releases (too low to be detected by the spore trap) early in the season, this might explain the missing lag phase in southern Victoria (22). Low airborne ascospore dose and a relatively low number of release events may explain the absence of a lag phase in the OR model, and also the lack of any need to include one when it is applied in Oregon (17). With only four to eight ascospore release events and low concentrations of airborne ascospores, an initial lag phase may appear to be absent. A relatively low number of release events might also produce a very shallow slope and extended distribution of the maturity curve toward the end of the ascospore maturity season. Ultimately, models incorporating a lag phase appear to be more broadly applicable in a variety of climates.

The IT model is a Gompertz equation and, thus, generates a relatively short initial lag phase compared with the logistic SV and NV models or probit-based NH model. In development of the IT model, the Gompertz equation was fitted to a data set representing trapping at a relatively low density, ranging from 131 to 3,824 ascospores $/ \mathrm{m}^{3}$ of air per year (15). The low density of ascospores may have concealed the lag phase as early- and late-season release events because a very low number of ascospores may be below the threshold of detection of these sampling methods (15).

The various models used different key events at the beginning of the growing season to initiate the accumulation of the independent variable (DDs) that drives the model. This event is commonly referred to as a biofix (2). The IT, OR, NV, and SV models used the first ascospore trapped as a biofix. In the present study, we used the median date of bud break for pear fruit buds within both forms of the NH model. However, both modeling approaches can be problematic. For example, reliance upon initial detection of ascospore discharge depends upon sensitive detection methods. Moreover, substantial maturation can take place in the absence of suitable release conditions. Thus, if ascospore trapping is used, the biofix may be detected only after a release event in which airborne ascospore density is above an often undefined detection threshold. Reliance upon host phenology also imposes certain limitations on mod- els. Bud break of pear coincided with first ascospore release in most years from Norway and Belgium. An important challenge remaining is the identification of a biofix to initiate DD accumulation in climates with relatively warm winter temperatures, to signal that the ascospore maturation process has begun. Bud break in such climates can occur over a period of several weeks, making the identification of a discrete phenological stage problematic (12). The foregoing may partially explain the discharge of ascospores before the defined phenological biofix (median bud break) in four seasons from northern Victoria and two seasons from southern Victoria (Table 2). The synchrony of pear bud break and initial ascospore maturation of $V$. pyrina in colder climates appears to be consistent in our studies (Table 2) and in previous reports for climates with relatively cold winters $(17,18)$. A similar synchrony of bud break and initial ascospore maturation in climates with cold winters has been reported for $V$. inaequalis (9). Given the protracted period of bud break in climates with comparatively little winter chilling, a stage of bud development occurring earlier than the median (e.g., 5 to $10 \%$ bud break) may be better correlated with initial ascospore maturity, and should be investigated if host phenology will be used as a biofix for the relevant models. Rossi et al. (15) suggested that a date during winter can be used as biofix for a model to estimate the date of initial ascospore maturity for $V$. pyrina, and such an approach might eventually reduce the need to

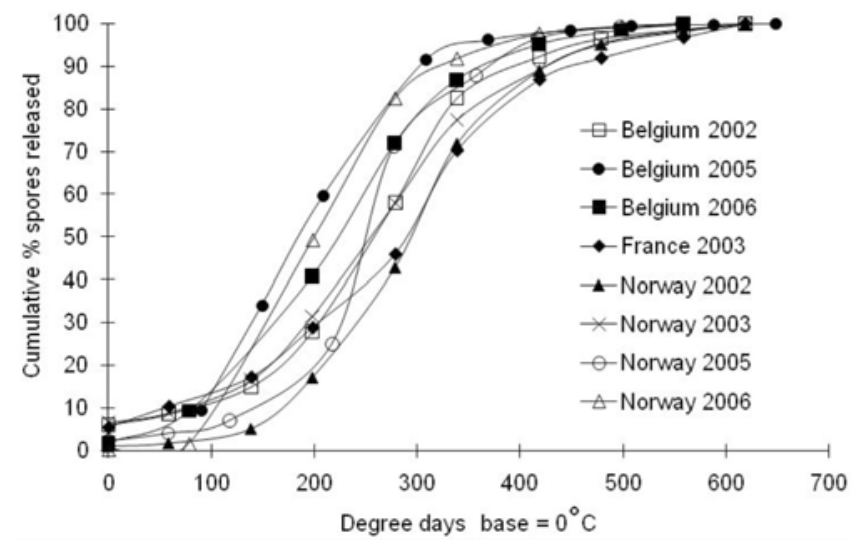

Fig. 3. Cumulative percent of Venturia pyrina ascospores released from eight samples of overwintered pear leaves collected at bud break at three different sites. Each data point is the mean of three replicates, each containing 10 leaf discs.

Table 4. Date of observed $95 \%$ ascospore release by Venturia pyrina compared to the date of $95 \%$ ascospore maturity as estimated by the models ${ }^{\mathrm{a}}$

\begin{tabular}{|c|c|c|c|c|c|c|c|c|}
\hline Location & Year & Observed $95 \%$ release & NH-1 & NH-2 & SV & NV & OR & IT \\
\hline Norway & 2001 & 29-Мау-2001 & 3 & 12 & 1 & 22 & 26 & 12 \\
\hline Norway & 2002 & 28-May-2002 & -5 & -2 & -6 & -1 & 15 & 6 \\
\hline Norway & 2003 & 26-Мау-2003 & 4 & 8 & 10 & -2 & 31 & 9 \\
\hline Norway & 2005 & 11-Jun-2005 & -7 & -1 & -2 & -7 & 20 & 6 \\
\hline Norway & 2006 & 27-Jun-2006 & -25 & -4 & -26 & -5 & -6 & 12 \\
\hline Norway & 2007 & 2-Jun-2007 & -7 & -2 & -2 & -2 & 14 & 15 \\
\hline Belgium & 2002 & 5-May-2002 & -16 & -3 & -11 & 1 & 14 & 5 \\
\hline Belgium & 2003 & 14-May-2003 & -15 & 0 & -10 & -2 & 30 & 4 \\
\hline Belgium & 2004 & 8-May-2004 & -10 & -10 & -9 & -5 & 17 & 1 \\
\hline Belgium & 2005 & 3-May-2005 & -2 & -2 & -3 & -8 & 23 & 0 \\
\hline Belgium & 2006 & 14-May-2006 & -7 & -7 & -7 & -9 & 13 & -1 \\
\hline Australia NV & 1993 & 2-Oct-1993 & 11 & 12 & 2 & 1 & 27 & -1 \\
\hline Australia NV & 1994 & 26-Oct-1994 & -7 & 0 & -13 & 1 & 7 & -14 \\
\hline Australia NV & 1996 & 19-Oct-1996 & -4 & -4 & -2 & 0 & 12 & -13 \\
\hline Australia NV & 1997 & 31-Oct-1997 & -12 & 0 & -23 & -22 & -2 & -24 \\
\hline Australia NV & 1998 & 7-Oct-1998 & 4 & 4 & 5 & 0 & 29 & 3 \\
\hline Australia SV & 1992 & 18-Oct-1992 & -2 & -2 & 5 & 1 & 29 & 1 \\
\hline Australia SV & 1993 & 9-Oct-1993 & 6 & 6 & 3 & 21 & 32 & -4 \\
\hline Australia SV & 1994 & 7-Oct-1994 & 8 & 20 & 4 & 0 & 32 & 1 \\
\hline Australia SV & 1997 & 18-Oct-1997 & -6 & -6 & -4 & -2 & 33 & -10 \\
\hline Australia SV & 1998 & $27-$ Oct-1998 & -25 & -25 & -16 & -21 & 9 & -16 \\
\hline
\end{tabular}

${ }^{a}$ Difference between observed and predicted $95 \%$ ascospore maturity/release (in days), where negative values mean that it is predicted too early and positive values too late. Models developed for V. pyrina in southern Victoria (SV), northern Victoria (NV), Oregon (OR), and Italy (IT) or for V. inaequalis in New Hampshire (NH-1) and modified in Norway (NH-2). 
depend upon tree phenology in climates where bud break is protracted and temporally heterogeneous.

The NH-2, NV, and IT models were designed to adjust for dry periods during the ascospore release season, using different moisture criteria to halt DD accumulation $(15,20,22)$. These models were consistently the most accurate predictors of $95 \%$ spore depletion, and the NH-2 and NV models yielded the best fit to observed spore release when fitting a pooled data set from all locations. The results from the laboratory experiments provide poor fits to the NV and IT models, indicating that, although the corrections employed for dry periods improve the fit for dry seasons, the corrections reduce the fit when moisture is not limiting. The criterion used to suppress DD accumulation during dry weather that was employed in the NH-2 model was empirically developed based upon a compromise to improve the fit during dry seasons, while not disrupting the fit to data from wet seasons (20). Both the NH-1 and NH-2 models estimated ascospore maturation similarly but the NH-2 model yielded more accurate predictions of $95 \%$ ascospore depletion. $\mathrm{NH}-1$ consistently predicted $95 \%$ ascospore maturation too early compared with $\mathrm{NH}-2$. In practical use, this form of error would result in underestimation of inoculum dose and the risk of infection; thus, the NH-2 model would likely be preferred by most advisory services.

Our study illustrated that a widely validated and refined model (NH-2) developed for the closely related causal agent of apple scab (V. inaequalis) may have wide applicability in modeling the development of $V$. pyrina across a broad range of climates, as long as a biofix can be accurately defined. In areas where protracted dry periods are common, models that do not correct for interrupted wetness may predict the end of the season too early.

\section{Literature Cited}

1. Buck, A. L. 1981. New equations for computing vapor pressure and enhancement factor. J. Appl. Meteorol. 20:1527-32.

2. Gadoury, D. M., and MacHardy, W. E. 1982. A model to estimate the maturity of ascospores of Venturia inaequalis. Phytopathology 72:901-904.

3. Gadoury, D. M., and MacHardy, W. E. 1984. A 7-day recording volumetric spore trap. Phytopathology 73:1526-1531.

4. James, J. R., and Sutton, T. B. 1982. A model for predicting ascospore maturation of Venturia inaequalis. Phytopathology 72:1081-1085.

5. Kienholz, J. R., and Childs, L. 1937. Twig lesions as a source of early spring infection by the pear scab organism. J. Agric. Res. 55:667-681.

6. Latorre, B. A., Yanez, P., and Rauld, E. 1985. Factors affecting release of ascospores by the pear scab fungus (Venturia pirina). Plant Dis. 69:213-216.

7. Lin, L. I.-K. 1989. A concordance correlation coefficient to evaluate reproducibility. Biometrics 45:255-268.
8. MacHardy, W. E. 1996. Apple Scab: Biology, Epidemiology, and Management. American Phytopathological Society, St. Paul, MN.

9. MacHardy, W. E., Gadoury, D. M., and Gessler, C. 2001. Parasitic and biological fitness of Venturia inaequalis: relationship to disease management strategies. Plant Dis. 85:1036-1051.

10. Marsh, R. W. 1933. Observations on pear scab. J. Pom. Hort. Sci. 10:71-90.

11. Massie, L. B., and Szkolnik, M. 1974. Prediction of ascospore maturation of Venturia inaequalis using cumulative degree-days (Abstr.). Proc. Am. Phytopathol. Soc. 1:140.

12. McArtney, S., Foote, K., Campbell, J., Palmer, J., and McGill, S. 2002. Investigation of bloom desiccants as organic thinners of apples. Proc. 1st Natl. Organic Tree Fruit Res. Symp. Grand Junction, CO.

13. O'Leary, A. L., and Sutton, T. B. 1986. The influence of temperature and moisture on the quantitative production of pseudothecia of Venturia in aequalis. Phytopathology 76:199-204.

14. Rossi, V., Ponti, I., Marinelli, M., Giosué, S., and Bugiani, R. 1999. Field evaluation of some models estimating the seasonal pattern of airborne ascospores of Venturia inaequalis. J. Phytopathol. 147:567-575.

15. Rossi, V., Salinari, F., Pattori, E., Giosué, S., and Bugiani, R. 2009. Predicting the dynamics of ascospore maturation of Venturia pirina based on environmental factors. Phytopathology 99:453-461.

16. Schwabe, W. F. S., Jones, A. L., and van Blerk, E. 1989. Relation of degreeday accumulations to maturation of ascospores of Venturia inaequalis in South Africa. Phytophylactica 21:13-16.

17. Spotts, R. A., and Cervantes, L. A. 1994. Factors affecting maturation and release of ascospores of Venturia pirina in Oregon. Phytopathology 84:260264.

18. Spotts, R. A., Cervantes, L. A., and Niederholzer, F. J. A. 2000. Pear scab: components of potential ascospore dose and validation of an ascospore maturity model. Plant Dis. 84:681-683.

19. Stensvand, A., Amundsen, T., and Semb, L. 1996. Observations on wood scab caused by Venturia inaequalis and Venturia pirina in apple and pear in Norway. Norw. J. Agric. Sci. 10:533-540.

20. Stensvand, A., Eikemo, H., Gadoury, D. M., and Seem, R. C. 2005. Use of a rainfall frequency threshold to adjust a degree-day model of ascospore maturity of Venturia inaequalis. Plant Dis. 89:198-202.

21. Stensvand, A., Gadoury, D. M., Eikemo, H., and Seem, R. C. 2006. Climatic conditions prior to green tip of apple affect ascospore maturation in Venturia inaequalis. IOBC Bull. 29:243-247.

22. Villalta, O., Washington, W. S., Kita, N., and Bardon, D. 2002. The use of weather and ascospore data for the forecasting of apple and pear scab in Victoria. Aust. Plant Pathol. 31:205-215.

23. Villalta, O., Washington, W. S., Rimmington, G. M., and MacHardy, W. E. 2001. Environmental factors influencing maturation and release of ascospores of Venturia pirina in Victoria, Australia. Aust. J. Agric. Res. 52:825837.

24. Villalta, O., Washington, W. S., Rimmington, G. M., and Taylor, P. A. 2000. Influence of spore dose and interrupted wet periods on the development of pear scab caused by Venturia pirina on pear (Pyrus communis) seedlings. Aust. Plant Pathol. 29:255-262.

25. Xu, X., and Butt, D. J. 1993. PC-based disease warning systems for use by apple growers. EPPO Bull. 23:595-600. 